IZA DP No. 8369

\title{
Progressive Taxation in a Tournament Economy
}

Jeffrey Carpenter

Peter Hans Matthews

Benjamin Tabb

August 2014 


\title{
Progressive Taxation in a Tournament Economy
}

\author{
Jeffrey Carpenter \\ Middlebury College \\ and IZA \\ Peter Hans Matthews \\ Middlebury College \\ Benjamin Tabb \\ Middlebury College
}

Discussion Paper No. 8369

August 2014

IZA

P.O. Box 7240

53072 Bonn

Germany

Phone: +49-228-3894-0

Fax: +49-228-3894-180

E-mail: iza@iza.org

Any opinions expressed here are those of the author(s) and not those of IZA. Research published in this series may include views on policy, but the institute itself takes no institutional policy positions. The IZA research network is committed to the IZA Guiding Principles of Research Integrity.

The Institute for the Study of Labor (IZA) in Bonn is a local and virtual international research center and a place of communication between science, politics and business. IZA is an independent nonprofit organization supported by Deutsche Post Foundation. The center is associated with the University of Bonn and offers a stimulating research environment through its international network, workshops and conferences, data service, project support, research visits and doctoral program. IZA engages in (i) original and internationally competitive research in all fields of labor economics, (ii) development of policy concepts, and (iii) dissemination of research results and concepts to the interested public.

IZA Discussion Papers often represent preliminary work and are circulated to encourage discussion. Citation of such a paper should account for its provisional character. A revised version may be available directly from the author. 


\section{ABSTRACT}

\section{Progressive Taxation in a Tournament Economy}

Not enough is known about the responsiveness of individuals, in particular those who tend to work under different incentives, to changes in marginal tax rates. We ask whether changes in marginal tax rates are less distortionary for workers engaged in a contest. To examine this potential rationale for a more progressive tax code, we first model the effort decisions of workers faced with progressive taxation under tournaments and piece rates. Because of the difficulty identifying any distortion that may be induced by the tax code in naturally occurring data, we then report on the results of a real-effort experiment based on this model. Consistent with a behavioral approach to public finance, we find that tournament workers are less sensitive, and conclude with a tentative evaluation of the welfare benefits of progressive taxation in tournament economies.

\section{NON-TECHNICAL SUMMARY}

Economists expect workers to adjust their efforts when tax rates change. Specifically, workers are expected to withhold effort when marginal tax rates increase because the net payoff from working is smaller. However, what if you are one of the many highly compensated workers employed under tournament incentives? If you work for a bonus or for a promotion you might not be so concerned about the marginal tax rate. Instead, you need to focus on winning these tournaments. If this is true, as our model and data suggest, there are large implications for the logic of progressive taxation. If tournament contestants do not pull back when the tax code becomes more progressive, the traditional argument against progressive taxation - it will cause too much distortion in the labor market - loses its power and overall welfare might actually rise as the tax code becomes more progressive.

JEL Classification: $\quad \mathrm{H} 20, \mathrm{H} 41, \mathrm{~J} 22, \mathrm{~J} 33, \mathrm{C} 91$

Keywords: taxation, tournaments, public good, real effort experiment

Corresponding author:

Jeffrey Carpenter

Department of Economics

Middlebury College

Middlebury, VT 05753

USA

E-mail: jpc@middlebury.edu 


\section{Introduction}

Renewed interest in the social and economic consequences of unequal income distribution has also stimulated new discussion about the costs and benefits of progressive taxation. In most but not all contributions to the literature, taxation is the means to income redistribution, the utilitarian benefits of which are weighed against various disincentive effects, the "leaks" in Okun's (1975) proverbial bucket. Diamond and Saez's (2011) much-cited recent case for high and rising marginal tax rates for high income earners is one of hundreds, if not thousands, of examples. A second, less common, approach emphasizes the provision of public goods in an unequal world, including, but not limited to, their redistributive properties, and derives the tax schedule as a solution to the "financing problem." In either case, however, the choice of schedule turns, in part, on the responsiveness of income earners - in particular, high income earners to variations in marginal tax rates. Our purpose in this paper is to draw attention to an important lacuna in the characterization of this response.

A number of recent studies have found that high income earners are less "tax sensitive" than once believed. Goolsbee's (2000) influential paper on executive compensation, for example, finds little or no evidence that taxable income decreases in the medium run, and identifies "compensation timing" as the source of almost all short term variation. Like other contributions to the "elasticities approach" (Saez 2001, Piketty, Saez and Stantcheva 2014), however, these are reduced form estimates and so we know much more about the magnitude of the response than its explanation.

The surprise, perhaps, is how few structural models are available to empirical researchers. Keane's (2011) authoritative review of the literature explores the empirical implications of three distinct models (static, simple life-cycle and life-cycle with human capital accumulation) but in each of these, the representative worker sells "labor time" in return for a fixed wage or time rate. Lemieux, MacLeod and Parent (2009), for example, find that more than $40 \%$ of male household heads in their PSID sample received some sort of "performance pay," a number that does not include, among others, those on promotion ladders whose income at each "rung" is more or less fixed. Furthermore, performance is often measured not in times of hours or weeks, but effective effort.

The emphasis on tournaments reflects two considerations. First, consistent with one of Lazear and Rosen's (1981) initial motivations for their model, tournaments are often used to characterize executive compensation, and for researchers interested in 
the response of high income earners to higher marginal tax rates, this is an obvious population to consider. Second, as Lazear and Oyer (2004) remind us, tournaments also capture several characteristic features of internal labor markets, in which the prizes are promotions to higher levels. Viewed from this perspective, the scope of our work is much broader than high income earners: as Osterman and Burton (2009) observe, internal labor markets remain an important feature of the economic landscape.

Our conjecture was that tournament workers in the tail of the income distribution would be less sensitive to changes in marginal tax rates for at least two reasons. First, when marginal rates are high, differences in prizes are smaller, and further incremental changes in the tax code should have a smaller effect. Second, tournament workers are competitive, and often find additional motivation in the "joy of winning." This encourages hard work even when incentives are blunted and further mitigates the effects of tax code changes. We posit, in short, that standard theoretical predictions about the disincentive effects of progressive taxation overstate their practical consequences for workers preoccupied with tournaments.

A more complete understanding of the incentive effects of progressive taxation in this setting therefore requires models that incorporate three basic features: alternative compensation schemes, possible behavioral influences on tax responsiveness and, in some cases, variation in effort rather than hours. The model in the next section is a first step in this direction. Building on the recent work of Persson and Sandmo (2005), we focus on the effort choices of tournament workers under different tax regimes, compared to a piece rate benchmark, with some allowance for worker competitiveness.

Because of all the standard difficulties with making inferences from observational data (e.g., selection, measurement error and endogeneity) we then turn to the experimental lab to offer a first test of our conjecture. To increase the external validity of our data, however, we conduct a real effort experiment designed to explore some of the model's implications. We compare effort choices under two tax regimes, one more progressive than the other, and under two compensation schemes, a simple piece rate and a tournament. An incidental but important feature of our design is that tax revenues are neither redistributed nor assumed to vanish into some "fiscal black hole," as in the past but are instead used to fund a public good whose benefits are salient to workers. We also collect data on individual characteristics and beliefs, including gender, competitiveness and political views.

Our main result is that while the introduction of more progressive taxes causes 
some distortion (effort does fall) under both compensation schemes, the difference-indifferences is negative, that is, it falls much less (indeed, in a statistical sense, almost not at all) under the tournament. In short, we find that the response of tournament workers is almost inelastic, a provocative result with profound implications for public finance. For example, if the executives Goolsbee (2000) studied were competitive tournament workers, the observation that their labor incomes are tax insensitive comes as no surprise.

We are not the first, of course, to explore the effects of tax changes in an experimental setting. It is important to note, for example, that our piece rate experiment replicates to a great extent what others have found. This increases the internal validity of our results by suggesting there is nothing idyosyncratic about our design. Sutter and Weck-Hannemann (2003), for example, find that individual effort falls as tax rates increase, but that the reduction is smaller when tax decisions are made behind the veil of ignorance. Ottone and Ponzano (2007) also find significant effort reductions but, in their case, the effect is limited to high tax rates (70\%, for example). Working with a much larger sample, Lévy-Garboua et al. (2009) reach a similar conclusion, and provide some evidence that it owes as much to fairness norms as the traditional logic of labor/lesiure tradeoffs. No less important for our work, there is also some experimental evidence that it isn't just the effective tax rate, but the progressivity of the entire tax code, that matters. Swenson (1988), for example, increased the tax rate and, as a consequence of a budget-balancing lump sum element of the code, its progressivity, and found a significant decline in effort. In a series of experiments, Sillamaa (1999 a, b, c) replicated Swenson's results and showed that a more progressive code (implemented through the construction of a Hausman equivalent code as a control) also reduced effort.

Our own design, discussed in more detail in the third section, differs from the others in at least three important dimensions. First, consistent with the previous discussion, we considered both piece rates (linking our results to the exisiting literature) and tournaments, our focus. Second, our treatment of taxes is more expansive: the convention has been to treat taxation as either confiscation (Sutter and Weck-Hannemann, 2003; Levy-Garboua et al., 2009) or redistribution (Swenson, 1988; Sillamaa, 1999a, b, c; Ottone and Ponzano, 2007) but in our experiment, revenues are used to fund a proper public good, one that is optimal to provide and vulnerable to free-riding. Third, we felt it important, if somewhat less transparent, for our participants to interact with 
the tax code itself, and not, as in almost all previous experiments, with a schedule of after-tax wages.

\section{Progressive Taxation and Tournament Incentives}

We first describe a simple model that provides a useful framework for evaluating our conjecture that the distortionary effects of progressive taxation might be smaller when workers vie for a prize (e.g., a bonus or a promotion) in a tournament, one that builds on the recent work of Persson and Sandmo (2005). Consider a representative firm with two workers, each of whom produces output $x_{i}=e_{i}+\epsilon_{i}$, where $e_{i}$ is normalized effort and $\epsilon_{i}$ is a mean zero random variable that is uncorrelated between workers. Each worker confronts the simplest possible progressive tax schedule, in which the total tax burden $\tau_{i}$ is equal to $t x_{i}-f$ where $t$ is the marginal tax rate and $f$ is just a lump-sum allowance. Given $f$ is constant, the average tax rate increases with income, consistent with standard notions of progressivity. In contrast to Persson and Sandmo (2005), however, workers in our setup also receive public good benefits equal to a fraction $\alpha$ of total tax revenues $t\left(x_{1}+x_{2}\right)-2 f$. Lastly, workers are assumed to be risk neutral, and experience a quadratic cost of effort schedule, $\frac{1}{2} k e_{i}^{2}$.

Consider first a piece rate regime in which the price of output is normalized to 1 and workers receive full market value for each unit produced. A risk neutral worker who maximizes the expected value of her after-tax income, net of effort costs and public good benefits, will solve the problem:

$$
\max _{e_{i}} e_{i}(1-t)+f-\frac{1}{2} k e_{i}^{2}+\alpha\left(t\left(e_{i}+e_{j}\right)-2 f\right)
$$

It is straightforward to show that each worker's optimal effort level is:

$$
e_{P}^{*}=e_{1, P}^{*}=e_{2, P}^{*}=\frac{1-(1-\alpha) t}{k}
$$

where " $P$ " denotes piece rate. As expected, effort decreases as $k$, and therefore the marginal cost of effort, rises and increases with $\alpha$, the rate of return on the public good, an important if sometimes overlooked response. Effort also decreases as the marginal tax rate $t$ rises, where the magnitude of the response does not depend on whether $f$ is adjusted to preserve tax revenue. The response does depend on both $\alpha$ and $k$, however: workers will reduce effort more when the marginal cost of effort is 
high and/or the return on the public good is low.

The worker's decision problem under the tournament regime is more complicated. We depart from the conventional "fixed prize" specification, and assume that the winner receives a share $s>1 / 2$ of firm revenues, the expected value of which is $e_{1}+e_{2}$, while the loser receives the residual, $1-s$. In other words, we consider tournaments that "balance the budget." The likelihood $P$ that worker $i$ wins the "lion's share" of the prize is just the likelihood that $i$ produces more than $j$, which in turn is equal to $G\left(e_{i}-e_{j}\right)$, where $G()$ is the distribution function for the noise difference $\epsilon_{j}-\epsilon_{i}$.

In this standard setup, if worker $i$ is risk neutral and maximizes expected gains, she solves:

$$
\begin{gathered}
\left.\max _{e_{i}} G()\left[(1-t) s\left(e_{i}+e_{j}\right)-f\right]+[1-G()]\left[(1-t)(1-s)\left(e_{i}+e_{j}\right)-f\right]\right) \\
-\frac{1}{2} k e_{i}^{2}+\alpha\left(t\left(e_{i}+e_{j}\right)-2 f\right)
\end{gathered}
$$

After some simplification, the first order condition for optimal choice of effort level $e_{i, T}^{*}$, conditional on $e_{j, T}$ can be written:

$$
(1-t)[G() s+(1-G())(1-s)]+\left((1-t)\left(e_{i, T}^{*}+e_{j, T}\right)(2 s-1)\right) g()-k e_{i, T}^{*}+\alpha t=0
$$

where $g\left(\epsilon_{j}-\epsilon_{i}\right)=d G / d\left(\epsilon_{j}-\epsilon_{i}\right)$ is the associated density function. It follows that in a symmetric equilibrium, in which $G\left(e_{1, T}^{*}-e_{2, T}^{*}\right)=G(0)=1 / 2$, (4) implies that:

$$
e_{T}^{*}=e_{1, T}^{*}=e_{2, T}^{*}=\frac{(1-(1-2 \alpha) t)}{2[k-2(1-t)(2 s-1) g(0)]}
$$

where " $T$ " denotes (T)ournament and $g(0)$, the value of the density function at 0 , can be interpreted as the precision of the output signal. If the difference in noise were normal, for example, with mean 0 and variance $\sigma^{2}, g(0)=1 / \sigma^{2} \sqrt{2 \pi}$ is inversely proportional to that variance. As with other tournament models, equilibrium existence requires "sufficient noise," that is, $g(0)<k / 2(1-t)(2 s-1)$.

We note that for all marginal tax rates below some threshold, existence is sufficient for equilibrium effort in tournaments to exceed effort under piece rates. In what follows, we shall refer to such tournaments as "productive." It comes as no surprise that, productive or no, effort decreases as the marginal tax rate increases: 


$$
\frac{d e_{T}^{*}}{d t}=-\frac{[k(1-2 \alpha)+4 \alpha(2 s-1) g(0)]}{2[k-2(1-t)(2 s-1) g(0)]^{2}}<0
$$

The question, however, is how this distortion compares with that under piece rates. The answer, implicit in (6) and more obvious, perhaps, in Figure 1, depends on the initial value of the marginal tax rate. ${ }^{1}$

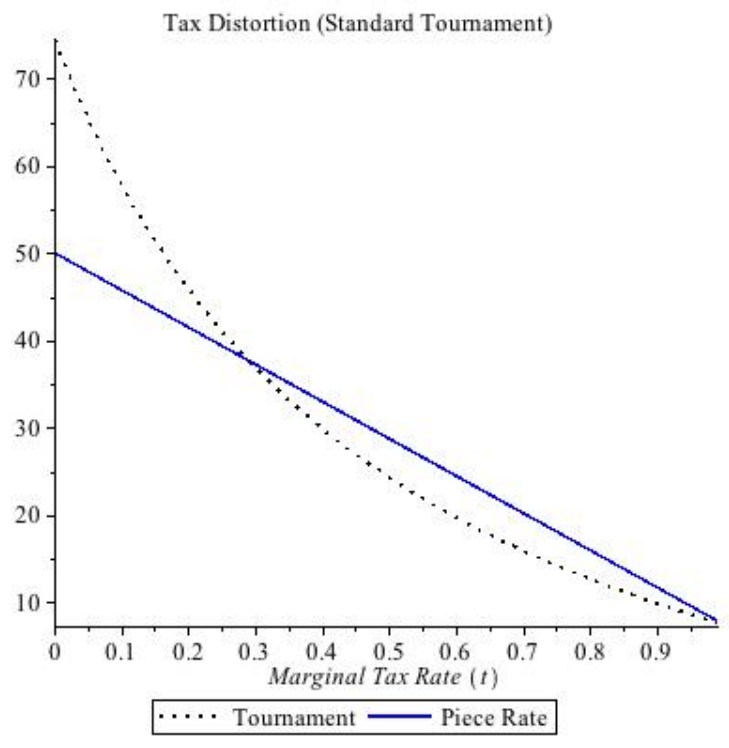

Figure 1: Effort as a Function of the Marginal Tax Rate.

Consistent with our initial conjecture, at sufficiently high marginal tax rates, optimal effort does fall more slowly in the tournament than under piece rates where effort declines at a constant rate (i.e., $d e_{P}^{*} / d t=-(1-\alpha) / k$, ). Consider the case in which the marginal tax rate $t$ approaches 1 . Workers under both regimes expend about $\alpha / k$ units of effort - in both cases, the existence of the public good rationalizes the expenditure of some effort, even at extreme tax rates - but it can be shown that tournament workers will be less responsive if $g(0)<k / 4 \alpha(2 s-1)$, which holds whenever the condition for tournament existence does. The problem, however, is that at some point equilibrium effort under tournaments falls below that under piece rates: for marginal tax rates in

\footnotetext{
${ }^{1}$ The parameter values used to construct Figures 1 and 2 reflect both the particulars of our experimental design and the results themselves: $s=0.6, \alpha=0.15, k=0.02$ and, based on a normal distribution with $\sigma=12, g(0)=1 / \sigma \sqrt{2 \pi} \approx 0.033$. When the marginal tax rate is $20 \%$, for example, the expected outputs of piece rate and tournament workers are, respectively, 41.5 and 45.7 units, similar, in both level and difference, to our experimental data discussed in the next section.
} 
this range, tournament workers are less responsive but also less productive. That is, there is, in this context, no reason for firms to adopt tournament-like schemes.

In its current form, however, the model does not account for the observation, wellestablished in the behavioral literature, that tournament workers are often more competitive than this. To this end, we consider how this framework should be modified to reflect this, and the consequences of this modification.

The most common manifestation of "competitiveness" in this context is a "joy of winning" that a number of studies now link to over-bidding in auctions (Delgado et al., 2008; Cooper and Fang, 2008; Dohmen et al., 2011; Astor et al., 2013) and overworking in contests and tournaments (Parco et al., 2005; Kraekel, 2008; Amaldoss and Rapoport, 2009; Sheremeta 2010; Chen et al., 2011; Altmann et al., 2012). Consistent with this behavioral research, we now allow tournament workers who produce more to experience the joy of winning, $\theta \geq 0$, and observe that the expected difference between winning and losing, a measure of the strength of the tournament's incentives, is equal to $(1-t)(2 s-1)\left(e_{i}+e_{j}\right)+\theta$, and therefore a decreasing function of the marginal tax rate $t$ but an increasing function of $\theta$.

If worker $i$ is risk neutral and maximizes expected gains, she now solves:

$$
\begin{gathered}
\left.\max _{e_{i}} G()\left[(1-t) s\left(e_{i}+e_{j}\right)-f+\theta\right]+[1-G()]\left[(1-t)(1-s)\left(e_{i}+e_{j}\right)-f\right]\right) \\
-\frac{1}{2} k e_{i}^{2}+\alpha\left(t\left(e_{i}+e_{j}\right)-2 f\right)
\end{gathered}
$$

After some simplification, the first order condition for optimal choice of effort level $e_{i, T}^{*}$, conditional on $e_{j, T}$ can be written:

$$
(1-t)[G() s+(1-G())(1-s)]+\left((1-t)\left(e_{i, T}^{*}+e_{j, T}\right)(2 s-1)+\theta\right) g()-k e_{i, T}^{*}+\alpha t=0
$$

where $g\left(\epsilon_{j}-\epsilon_{i}\right)=d G / d\left(\epsilon_{j}-\epsilon_{i}\right)$ is the associated density function. It follows that in a symmetric equilibrium, in which $G\left(e_{1, T}^{*}-e_{2, T}^{*}\right)=G(0)=1 / 2$, (8) implies that:

$$
e_{T}^{*}=e_{1, T}^{*}=e_{2, T}^{*}=\frac{(1-(1-2 \alpha) t)+2 g(0) \theta}{2[k-2(1-t)(2 s-1) g(0)]}
$$

As above, we note that while the existence of a tournament equilibrium depends on the marginal tax rate $t$ and winner's share $s$, it does not depend on winner's joy. 
We shall focus on configurations of parameter values for which tournaments elicit more effort, ceteris paribus. ${ }^{2}$ We know from (9) that tournament effort falls as output signals become less precise, and further observe when the noise becomes so large that the tournament amounts to a coin toss, the expected marginal benefit for either worker reduces to $(1 / 2)(1-t)+\alpha t$, which is constant, independent of effort and, most salient, the equivalent of a reduced piece rate. At lower noise levels, however, tournament workers are more productive than their piece rate counterparts: the effort level in (9) exceeds that in (2) whenever:

$$
g(0)>\frac{k(1-t)}{2[k \theta+2(2 s-1)(1-t)(1-t(1-\alpha))]}
$$

which establishes the expected lower bound on precision. Furthermore, because this lower bound is, for all admissible values of the relevant parameters, less than the upper bound required for existence, there must be some noise levels at which tournaments are "successful."

Again, our central concern in this section is whether tournament workers will be more or less responsive to changes in the marginal tax rate. The responsiveness of tournament workers can be written:

$$
\frac{d e_{T}^{*}}{d t}=-\frac{[k(1-2 \alpha)+4(2 s-1) g(0)(\alpha+g(0) \theta)]}{4[k-2(1-t)(2 s-1) g(0)]^{2}}
$$

The most important feature of (11) is that the responsiveness of tournament workers remains less sensitive at higher tax rates. There will be some tax rate at which their response to increased (or decreased) tax rates will become more muted than the response of piece rate workers.

\footnotetext{
${ }^{2}$ Again, these parameters are also consistent with the experiment.
} 


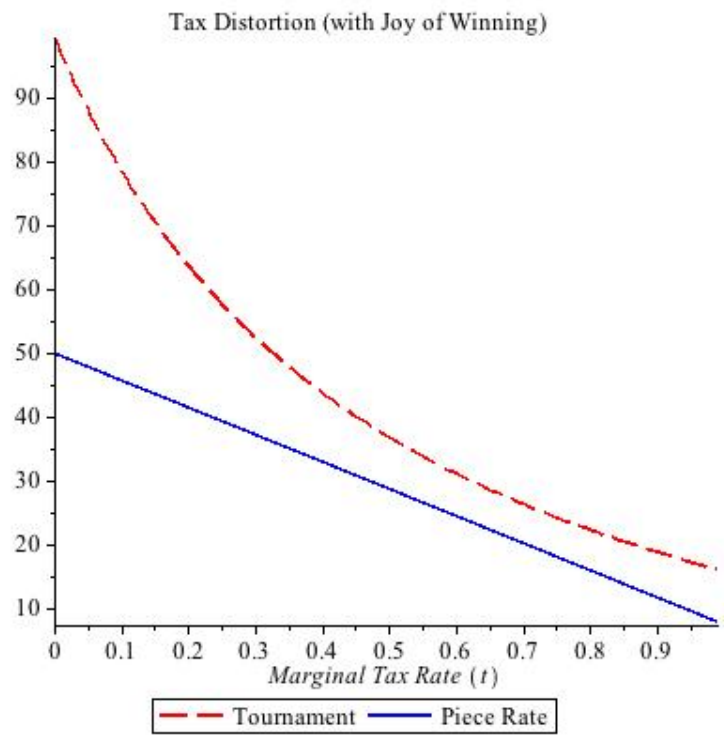

Figure 2: Effort as a Function of the Marginal Tax Rate (with a Joy of Winning).

The dashed line in Figure 2 depicts equilibrium effort in the tournament when there is a small (relative to observed output levels) winner's joy, in this case $\theta=5$. The first unmistakeable difference with Figure 1 is that tournament equilibria are productive at all marginal tax rates. The surprise here is not that tournament workers expend more effort when winners anticipate an additional benefit but rather that the effect is so large, at least in this case. Some intuition for this can be found in the size of the (vertical) shift, which measures the rise in tournament output at fixed tax rates: for $t=0.20$, for example, the prospect of a winner's joy that is the equivalent of 5 units of output causes each worker to increase her output from 45.9 to 63.7.

The second, even more important, difference is that for tax rates above some threshold, the dashed "tournament with joy" locus remains flatter than the piece rate line. In practical terms, if tournament workers are even slightly competitive, then the tournament will be productive and labor supply under moderate or high tax rate regimes will be continue to be less sensitive to variations in that rate, a result with important practical implications. For the case depicted in Figure 2, the marginal tax threshold is high $(67 \%)$ but not unprecedented. 


\section{Evidence from a Real Effort Experiment}

The pursuit of credible estimates of the responsiveness of workers to changes in marginal tax rates, at both the intensive or extensive margins, remains a feature of the public finance literature. Not only are there obvious sources of endogeneity in naturally occurring data (Keane, 2011), the quality of the data presents another challenge. For example, it is often hard to distinguishing the shift in compensation timing from permanent shifts in compensation and tax code changes tend to affect rates as well as brackets and the definition of taxable income, itself (Goolsbee, 2000).

Rather than struggle with these common empirical issues, we offer a first examination of the main hypothesis developed in Section 2 (that the tax responsiveness of workers depends on how they are incentivized) in a setting in which identification can be guaranteed. We conduct an experiment in which workers are hired and randomly assigned to an incentive structure and a tax code. This allows us to estimate the causal effect of the tax code on effort for different compensation schemes. As a result, we test whether the hypothesis holds when internal validity is guaranteed before examining the idea using naturally occurring data. That said, to push as far as possible on the external validity of our results, our experiment requires participants to put forth real effort. They actually work and their compensation depends on how hard they work. The details and results are explained below.

\subsection{Experimental Design}

Our participants completed a task similar to the ones used previously in this area of research (e.g., Sillamaa, 1999(a,b,c); Lévy-Garboua et al., 2009). They deciphered numbers (from 1-99) into letters using a decoding sheet. On the computer screen the participant was presented five numbers and an input box to type the corresponding letters. ${ }^{3}$ After decoding a "set" of five numbers, the participant would click a button, the computer would check to see if the set had been decoded correctly, and, if it had, the participant would be given another five numbers to decode. An error message was displayed if the set was decoded incorrectly and the participant was given as many chances as necessary to get it right. There was no limit to the number of sets a participant could decode in the time provided. The task was chosen because it had little intrinsic reward and ability was unlikely to be tied to demographics.

\footnotetext{
${ }^{3}$ The experiment was programmed in z-Tree, Fischbacher (2007).
} 
In each session of the experiment, nine participants were randomly sorted into three "firms" that formed a small scale economy in which people worked, paid taxes and the taxes were use to provide a public good. Our experiment employed a twoby-two factorial design. We utilized two, simple, five-bracket tax codes. The first was relatively flat and the second was considerably more progressive. We chose to vary the progressivity of the tax code instead of comparing a simple flat tax to a progressive one because we worried that the flat code would also just be simpler to understand and this simplicity could affect behavior. 4 The "flatish" tax code was based, loosely, on the U.S. tax code during the Clinton administration, the brackets progressed from $15 \%$ to $35 \%$ in equal steps (i.e., 15\%, 20\%, 25\%, 30\%, 35\%). The "progressive" tax code resembled the U.S. code during the great depression era. It started at just $5 \%$ but climbed to $64 \%$ at the highest bracket. Because the bracket earning intervals were fixed across codes to simplify them and we wanted to devise a progressive code that would be incidence-neutral when compared to the flatish code for the average participant, the progressive rates of $5 \%, 17 \%, 32 \%, 47 \%$, and $64 \%$ could not increase in fixed steps. Instead, the progressive rates were calibrated to the performance of the average worker in three initial flatish code sessions. This process proved successful - the incidence, at the individual level, did not differ significantly by the tax code imposed $(\mathrm{p}=0.77) .^{5}$

We also employed two compensation schemes. As is common in this literature (e.g., Swenson, 1988), participants were paid a piece rate in the first scheme. For each set that they correctly decoded they earned ten cents of pre-tax earnings. The second compensation scheme was a rank-order tournament. Here each correctly decoded set generated ten cents of pre-tax earnings for the firm. The person who decoded the most sets was awarded $60 \%$ of firm earnings, the person who decoded the second most sets was given $30 \%$ of the earnings and the lowest producer earned the remaining $10 \%$.

The collected tax revenue was used to fund a public good. However, because we did not want participants to focus too much attention on this benefit, the returns were modest. For every dollar of tax revenue collected in the economy, each of the nine workers received fifteen cents. This return is slightly more than the $1 / 9$ lower bound that ensures the public good is worth providing (i.e., socially optimal to provide) but

\footnotetext{
${ }^{4}$ This seems to have been a reasonable fear. Abeler and Jäger (2013) find, in a similar real effort setting, that the complexity of the tax code affects the extent to which workers respond to code changes.

${ }^{5}$ See the experimental instructions in the appendix for the details of the bracket limits and how the codes were implemented.
} 
it is well below the upper bound of 1, the constraint that makes it preferable (i.e., individually rational) to free ride, given the opportunity.

Considering the protocol, each session, regardless of treatment, had three work periods. The first lasted three minutes, was unpaid, and familiarized the participants with the software and the task. This was followed by two twelve-minute paid work periods. Again, to keep things as simple as possible, during each session the tax code was fixed for the two work periods but the compensation scheme changed between the first paid work period and the second. The order in which the compensation scheme changed (i.e., piece rate to tournament or tournament to piece rate) was determined randomly. Because the cryptography changed at the beginning of each period and the task was simple, we predicted experience would have little effect on productivity. ${ }^{6}$

We conducted twelve sessions, each lasting about 45 minutes, and therefore gathered 216 output observations from 108 participants. The average (take home) earnings of our participants was $\$ 14.84$, including a $\$ 5$ show-up payment. Weeks prior to participating, subjects answered a brief survey as part of the recruitment process. From this data we learned that $43 \%$ of our participants were female, $77 \%$ considered themselves to be competitive (i.e., they responded "generally competitive" or "extremely competitive" to a direct prompt), $17 \%$ classified themselves as politically conservative (i.e., they responded "independent lean republican", "republican" or "strong republican"), and $26 \%$, when asked to pick between two statements, chose "Government is almost always wasteful and inefficient" over "Government often does a better job than people give it credit for." Summary tests reported in Table 3 of the appendix based on these survey results suggest that our recruitment was balanced. The one exception was that there were significantly more participants in the progressive treatment that thought that government is wasteful. However, as the analysis described below suggests, these opinions do not have much effect on effort choices.

\subsection{Effort Choices}

As is common in the real effort paradigm, our participants worked hard; however, there was variance in their efforts. The overall mean output per work period was 45.74 sets (or 3.81 per minute) but the outputs ranged from a low of 25 sets to a high of 70 sets. Across treatments, the taxes paid on the resulting earnings averaged $\$ 1.03$ per work

\footnotetext{
${ }^{6}$ In fact, the results presented in the appendix (Table 3 ) confirm there were no productivity gains in the second work period.
} 
period which worked out to be an average effective tax rate of $19 \%$. As mentioned above, our tax code calibration worked well in that the individual taxes paid between the two codes did not differ significantly.

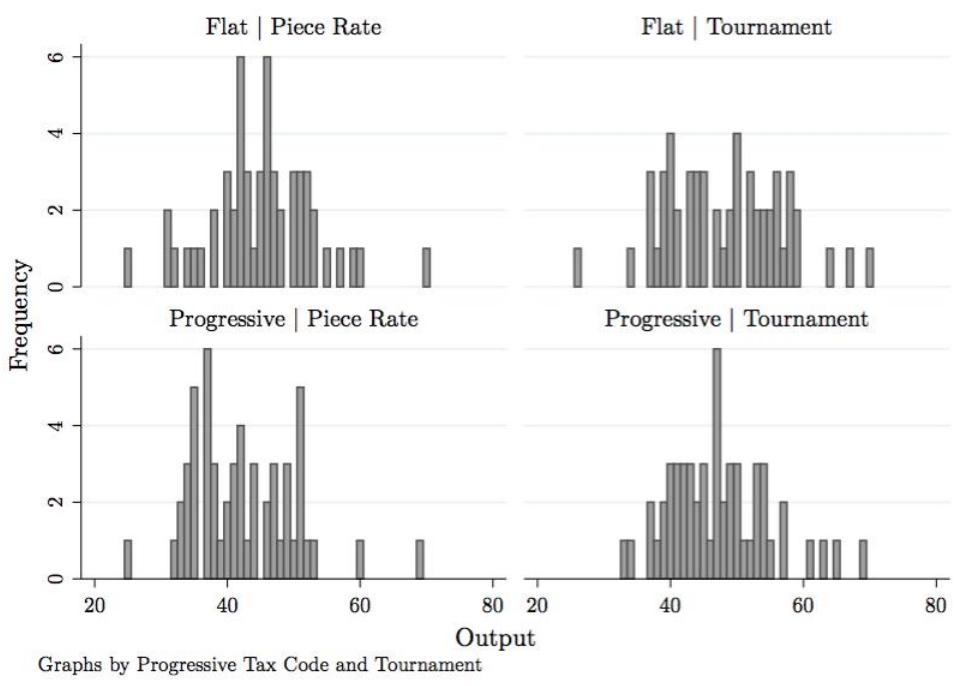

Figure 3: Effort Provided (by treatment).

We begin our analysis of any treatment differences visually using Figure 3 which illustrates the distribution of output by condition. As one can see on the left side of the figure, we, at least partially, replicate previous results in that under piece rates the progressive code does seem to dampen efforts to some extent. Replicating the related experimental literature on contests (summarized in Charness and Kuhn, 2011 and Dechenaux et al., 2012), we also see that the rank order tournament causes our participants to work a bit harder, in this case, regardless of the tax code. Overall, the positive effect on effort of the tournament appears to be stronger and more consistent than the negative effect of progressive taxation.

\begin{tabular}{r|cc|c}
\hline & Piece Rate & Tournament & $p$-value \\
\hline Flat Tax Code & $45.20(7.91)$ & $48.19(8.79)$ & 0.07 \\
Progressive Tax Code & $42.37(7.82)$ & $47.22,(7.58)$ & $<0.01$ \\
\hline$p-$ value & 0.06 & 0.54 &
\end{tabular}

Table 1: Mean Effort (s.d.) and Summary Results. 
To get a better sense of the treatment effects, consider Table 1. Indeed, as predicted, mean output under piece rates falls from 45.20 sets to 42.37 as the tax code becomes more progressive. This constitutes a $6 \%$, marginally significant $(\mathrm{p}=0.06)$, reduction in output. Compared to previous results, discussed in the introduction, this reduction is modest but one plausible explanation is that our participants might have been less averse to taxes because the tax revenue provided a public good instead of being confiscated. Comparing across columns, we confirm that the tournament had a more consistent effect on output. In the case of the flatish code, output increased by $7 \%$ and in the case of the progressive code, the increase was $11 \%$. These differences are similar in magnitude to those found in previous tournament experiments (e.g., van Dijk et al., 2001). The most important difference in Table 1, however, lies in the right column. Here we see that the progressive tax code did not cause a significant reduction in effort when tournament incentives were being used. Although mean output falls from 48.19 to 47.22 , the resulting $2 \%$ reduction is far from significant.

\begin{tabular}{lccc}
\hline & $(1)$ & $(2)$ & $(3)$ \\
\hline Progressive Code (under Piece Rates) & $-2.87^{*}$ & $-3.66^{* *}$ & $-3.66^{* *}$ \\
& $(1.71)$ & $(1.78)$ & $(1.73)$ \\
Progressive Code (under Tournament) & -0.92 & -1.35 & -1.38 \\
& $(1.67)$ & $(1.70)$ & $(1.63)$ \\
Tournament (under Flat Code) & $2.95^{*}$ & $2.80^{*}$ & $2.86^{*}$ \\
& $(1.66)$ & $(1.70)$ & $(1.65)$ \\
Tournament (under Progressive Code) & $4.90^{* * *}$ & $5.12^{* * *}$ & $5.15^{* * *}$ \\
& $(1.76)$ & $(1.73)$ & $(1.67)$ \\
\hline Controls for experiment order. & Yes & Yes & Yes \\
Controls for covariates. & No & Yes & Yes \\
Controls for interactions. & No & No & Yes \\
\hline Observations & 216 & 210 & 210 \\
Adjusted $R^{2}$ & 0.05 & 0.06 & 0.12 \\
\hline Note: Dependent variable is individual output; OLS with robust (standard errors); \\
$*$ p $<0.10, * * \mathrm{p}<0.05, * * * \mathrm{p}<0.01$. & & &
\end{tabular}

Table 2: Average (Estimated) Marginal Treatment Effects.

To be more careful about our estimates, in Table 2 we calculate the average marginal effects of the treatments, controlling for both experiment order and the demographics 
we collected from the recruiting survey. For simplicity we report only the effects of direct interest, but a full table of results can be found in the appendix (i.e., Table 4). In column (1) we control for the order of the experiment which has little effect on our estimates. We continue to find that progressive taxation reduces output under piece rates by $6 \%(A M E=-2.87, \mathrm{p}=0.09)$ and that the tournament increases output by $6.5 \%(A M E=2.95, \mathrm{p}=0.07)$ with the flatish code and by $11 \%(A M E=4.90$, $\mathrm{p}<0.01$ ) with the progressive code. We also continue to find no significant reduction in output when taxes become more progressive and participants are competing in a rank-order tournament $(A M E=-0.92, \mathrm{p}=0.58)$. In column (2) of Table 2 we add the demographic covariates. This addition has modest effects on our estimates, the largest being that the drop due to tax progressivity in the piece rate treatment increases a bit (in magnitude and significance) to $8 \%(\mathrm{p}=0.04)$. In column $(3)$ we see that our estimates of the average marginal effects are not affected by the inclusion of interactions between the treatments and the demographic covariates (though Table 4 in the appendix suggests that some of the interactions are interesting). To summarize, our estimates of the treatment effects replicate a number of studies in the related experimental literatures which is comforting in that this suggests that our proceedures are not unique, nor are they directly responsible for our results. The noteworthy finding of our experiment, however, is that tournaments not only attenuate, they appear to nullify, any disincentive effect of progressive taxation.

Our data is consistent with the theoretical predictions in Section 2: optimal effort ought to fall under both piece rates and tournaments as the tax code becomes more progressive but, conditional on the presence of even limited competitiveness, optimal effort in tournaments should decrease less. Not only do we confirm all three of these predictions in our data, the last result on the difference in progressivity differentials seems particularly strong. We were therefore especially keen to evaluate the hypothesis that competitive participants in rank-order tournaments are less sensitive to changes in tax incidence. In behavioral terms, if one is focused on winning the tournament (see, for example, Sheremata, 2010), tax code differences lose some salience. 


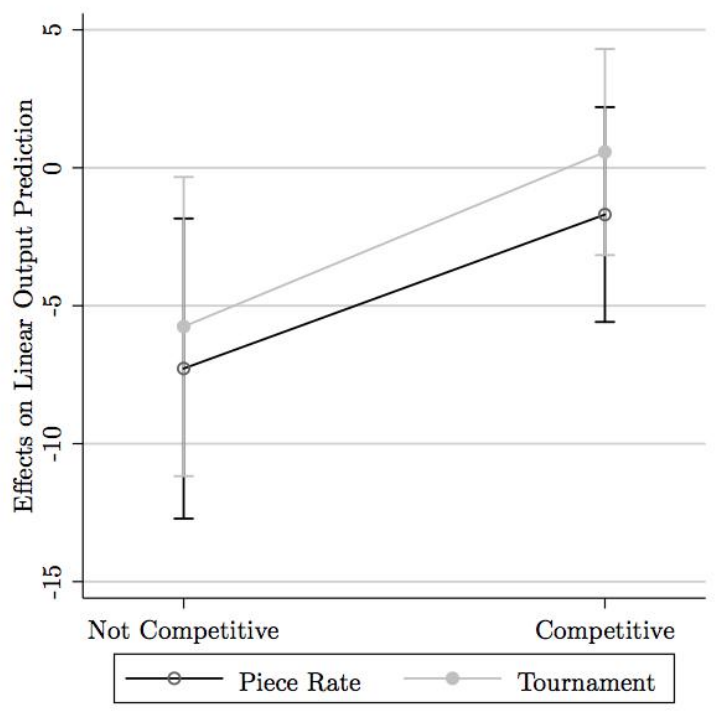

Figure 4: Average Marginal Effects of Tax Progressivity by Competitiveness (with $95 \% \mathrm{CIs})$.

Our survey data, allow us to test this auxiliary hypothesis about the role of competitiveness directly. The results are summarized in Figure 4. Using the same specification at the heart of Table 2, we parse the average marginal effect of the progressive tax code on participants in the tournament into the effects for competitive and non-competitive participants. The difference in the marginal effects is large and significant $(\mathrm{p}<0.05)$. Non-competitive tournament participants reduce their efforts by an average of 5.75 sets $(\mathrm{p}<0.01)$ while the competitive participants seem to ignore the tax code. Their efforts actually increase slightly, though not significantly $(\mathrm{p}=0.77)$. This confirms that competitive participants tend to ignore the tax code when participating in a tournament. As one can also see in Figure 4 the blinding effects of competitiveness seem to extend past the tournament. Competitive piece rate workers also only reduce their efforts 1.70 sets after the tax hike $(\mathrm{p}=0.39)$ compared to the non-competitive workers who reduce their efforts much more, an average of 7.28 sets $(\mathrm{p}<0.01)$.

In sum, our results are consistent with a behavioral public finance model in which workers maximize a traditional objective function augmented by a small "joy of winning." It is worth adding, however, that if more competitive workers sort into tournaments outside the lab, the effects of more progressive taxes could be even more diluted than what we find. 


\subsection{Welfare}

Our treatments were designed to focus on the curvature, but not the incidence, of the tax code. Our results, in turn, provide an alternative, and we believe important, rationale for progressive taxes. The standard argument, first codified in Mirrlees (1971), focuses on the trade-off between redistribution (which, under some utilitarian specifications, increases social welfare) and incentive distortion. Diamond and Saez's (2011) recent claim, for example, that current top marginal tax rates are much too low is a provocative contribution to the literature. The framework described here differs in at least two important senses from this one. First, the role of the state in both the model and the experiment is to provide public goods, not redistribute income, and there is no presumption that marginal utilities of income decline. Second, unlike the reduced form elasticities characteristic of the recent work of Piketty et al (2014) and others, we provide behavioral foundations for variations in tax responsiveness.

To provide some intuition, consider the effects of the (more) progressive tax code under tournament compensation. Consistent with Goolsbee (2000), who found that executive labor income did not respond much, at least in the medium term, to changes in the tax code, the effort level of tournament workers in our experiment is not tax sensitive. To see this, consider the first panel in Figure 5, which plots the (cumulative) distributuion functions of pretax income under the two tax regimes. We know, from the previous section, that mean output isn't much affected, but as the data attest, the invariance is more fundamental: using the Kolmogorov-Smirnov test, one cannot reject the null ( $p=0.613$ ) that the two distributions of income are the same. In more provocative terms, there is little evidence of the deadweight losses associated with changed incentives.

The imposition of a more progressive tax code should (still) alter the distribution of tax revenues, of course, and the second panel of Figure 5 confirms this. Both low and high tax bills are more common, and the null that the distribution of tax revenues is equal can be rejected at better than the one percent level $(p=0.001)$ under the Kolmogorov-Smirnov test. The increase in mean tax revenues, depicted in the same diagram as two vertical lines, is also substantial (almost 20\%) if not significant at the 10 percent level $(p=0.283)$. This means, of course, that tournament workers receive more of the public good, without the usual deadweight losses. Furthermore, we should expect to observe this even if, as our earlier model assumes, workers are ex ante identical. In terms of our notation, identical workers will expend the same effort $e_{i}$ but 
produce (or be observed to produce) different levels of output $x_{i}$, with an increased tax burden on (at least) the fortunate "winner."7

\section{Tournament}
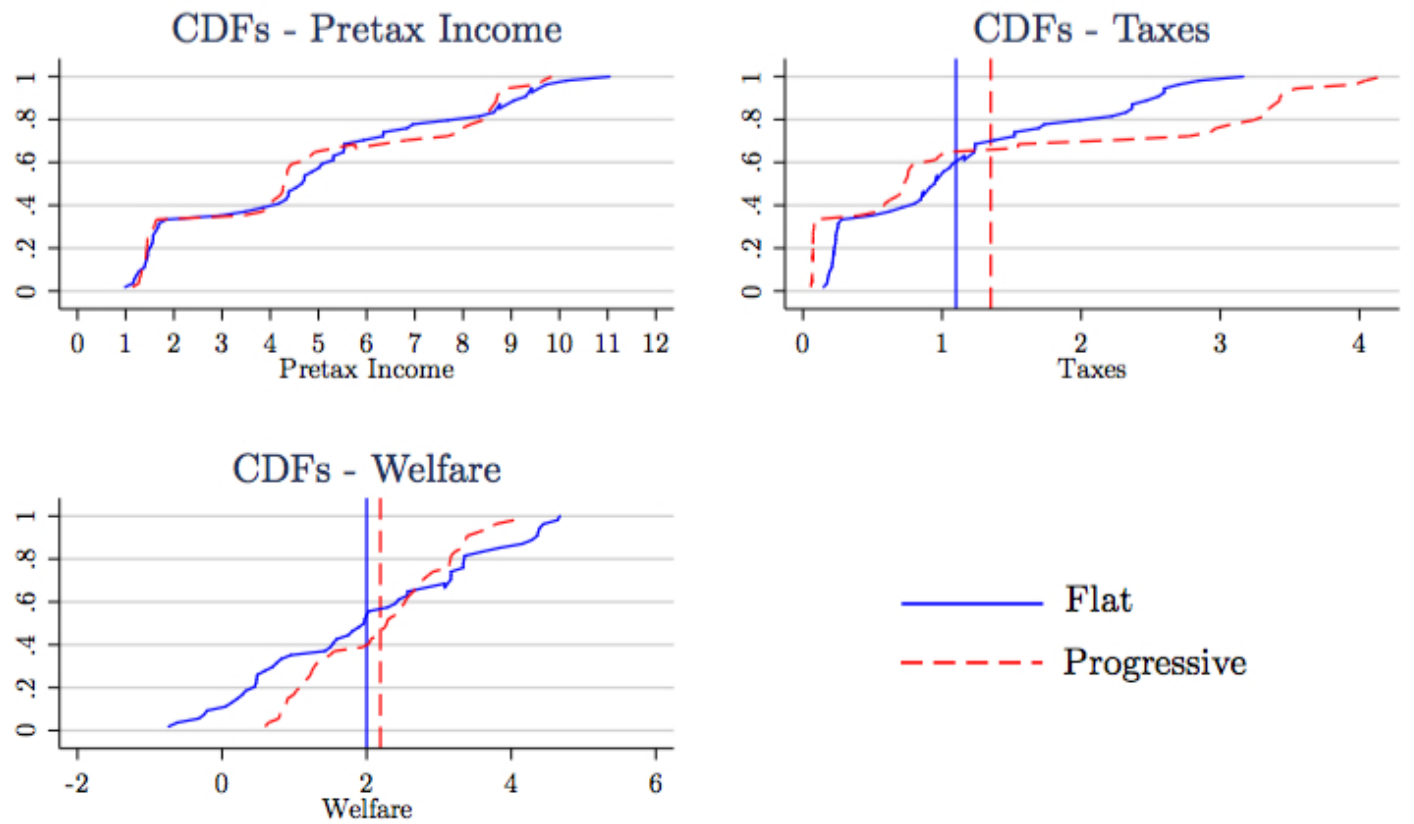

Figure 5: Distribution Functions Under Tournaments

The welfare consequences of progressive taxation are more difficult to measure. It is common in the experimental public goods literature, at least as a first approximation, to equate "material benefits," defined here as after-tax income plus public goods benefits, and welfare. This is straightforward to calculate - both components are observed - but given our interest in the relationship between taxes and effort, also misleading. The challenge, of course, is that within this framework, the cost of effort is not observed, and so must be inferred. To do so, we exploit the properties of our model, in which the cost of effort was assumed to be $\frac{1}{2} k e^{2}$. The equilibrium condition for piece rate workers (2) implies that $k$ will be equal to the ratio of the constant (and independent

\footnotetext{
${ }^{7}$ As an aside, our tournament model is therefore consistent with the "luck egalitarianism" of Dworkin (2000) and others.
} 
of the number of workers) marginal benefit of effort, $1-(1-\alpha) t$, to the (common, for identical workers) equilibirum effort level $e^{*}$. What we observe, of course, is not $e^{*}$, but $x_{i}=e^{*}+\epsilon_{i}$, but if one is prepared to assume that the distribution of $\epsilon_{i}$ is uniform and symmetric about zero - a not unreasonable assumption, given the distribution of observed output - then the median of the random variable $\widetilde{k}=(1-(1-\alpha) t) / x$ will equal $k$. With this in mind, we estimated $k$ with the sample median of $\widetilde{k}$.

Even if $k$ were known a priori, however, $(1 / 2) k x_{i}^{2}$ would be a biased estimate of the worker $i$ 's cost of effort. We know the mean bias, however, and can correct for this: the expected value of the difference between $(1 / 2) k x_{i}^{2}$ and $(1 / 2) k e_{i}^{2}$, or $1 / 2 k E\left(x_{i}^{2}-e_{i}^{2}\right)=$ $1 / 2 k E\left(\epsilon_{i}^{2}+2 e_{i} \epsilon_{i}\right)=1 / 2 k \sigma^{2}$, where $\sigma^{2}$ is the variance of output, for which there is the sample estimate $s^{2}$.

With this in mind, we calculate individual welfare as the sum of after-tax income and public goods benefits, less the estimated cost of effort $(1 / 2) \hat{k}\left(x_{i}^{2}-s^{2}\right)$, and plot the distribution functions under the two tax schemes in the third and last panel of Figure 5. It is clear, and not suprising, that fewer workers find themselves below low, even moderate, welfare thresholds under more progressive taxation: indeed, while welfare is negative for almost 10 percent of tournament workers under the flat tax - that is, if our estimates of the costs of effort are plausible, almost one in ten workers is made worse off - the welfare of all workers is positive under the progressive tax. There are two reasons for this. First, while the pre-tax incomes of low-income workers are not much affected, after-tax income increases as the tax code becomes more progressive. Second, the increase in average/total tax revenue also increases public goods benefits. At the other end of the income distribution, however, fewer workers experience high welfare under progressive taxation.

The total gains of progressive taxation exceed the total losses, however, and mean welfare, depicted in the same panel with a pair of vertical lines, increases almost 10 percent, but the difference is not statistically significant $(p=0.455)$. Under the Kolmogorov-Smirnov test, however, the null that the welfare distributions are the same can be rejected, at better than the 5 percent level $(p=0.029)$. We conclude that for these tournament workers, there is little or no evidence of the traditional efficiency losses associated with more progressive taxation/more equitable distribution of benefits, and some evidence that progressive taxation increases material social welfare. If

\footnotetext{
${ }^{8}$ Given the small differences in observed effort across these treatments, the results are robust with respect to small differences in the calculation of effort costs.
} 
robust, these results represent an important amendment to conventional wisdom about taxation. ${ }^{9}$

\section{Piece Rate}
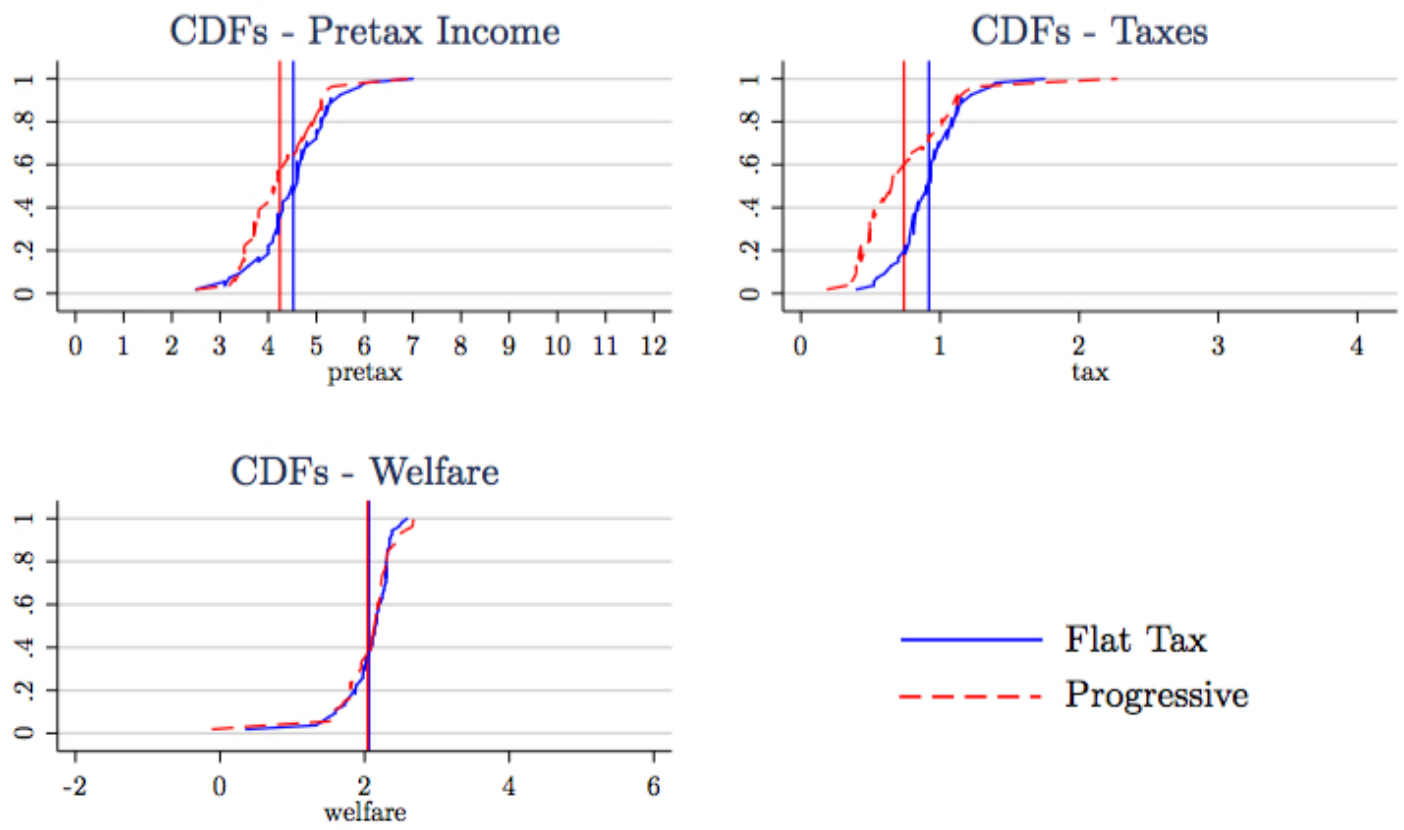

Figure 6: Distribution Functions Under Piece Rates

The welfare implications of progressive taxation under piece rates are also surprising, but for quite different reasons. Consider the cumulative distributions of pretax income, depicted in the first panel of Figure 6. The differences must be interpreted with some care because our initial calibration did not guarantee that within the piece rate regime, tax burdens would be unchanged at initial effort choices, but it appears that the empirical distrbution of pretax income under the flat schedule almost dominates (in a first order sense) the distribution under the progressive schedule. The null

\footnotetext{
${ }^{9}$ We should note that a complete accounting of the welfare changes associated with more progressive taxation would also include behavioral costs and benefits, one example of which is the joy of winning $\theta$ tournament winners may experience. There is reason to be circumspect about such calculations, however. It is difficult to disentangle this "joy of victory" from the "agony of defeat," for example, even if these (at least) shift the distribution of welfare in different directions. This said, if these distributions shift the same amount, our conclusions are more or less unaffected.
} 
that the two distributions are the same can be rejected at the 10 percent, but not 5 percent, level $(p=0.063)$, as can the null that the means of the two distributions are the same $(p=0.064)$. Consistent with more orthodox treatments of taxation, there is evidence of a disincentive effect and, therefore, deadweight loss.

Much the same can be said about the distributions of individual tax revenues in the second panel of Figure 6. Large tax bills are a little more common under the progressive scheme, small and medium bills are more common under flat taxes, but the second effect dominates, and the reduction in the average tax bill, depicted as the two vertical lines in the same panel, is substantial (more than 15 percent) and significant at better than the 1 percent level $(p=0.004)$. Using the Kolmogorov-Smirnov test, the null that the two distributions are the same is likewise rejected $(p=0.000)$. The surprise, perhaps, is found in the distributions of material welfare under the two tax regimes, depicted in the third panel. Visual inspection suggests, and the usual tests confirm, that there are no significant differences in the welfare distributions or their first moments. That is, despite evidence of incentive effects similar to those from previous experiments, the net social welfare costs of progressive taxation seem minimal.

\section{Discussion}

It was our initial intuition that workers who are concerned, for both strategic and behavioral reasons, with their rank within internal labor markets would be less sensitive to variations in the tax code. If so, the usual disincentive effects of progressive taxation would be attenuated, with important welfare implications, more so when tax revenues are used to finance productive public goods.

We are able to write down a model that accommodates this intuition, and find support for it in our experimental data. As in the previous literature, progressive taxation distorts incentives under piece rates. We do not find, however, that this effect is large enough to reduce welfare. At the same time, with tournaments effort increases and is more or less inelastic with respect to the marginal tax rate. Given the increase in total tax revenue, mean welfare actually increases as more public goods are provided.

Our results suggest that as tournament-like compensation becomes more common, the "welfare differential" between tax regimes should decrease, and even reverse itself, without substantial decreases in mean welfare. To explore this proposition in more detail, we conduct a simulation-based "thought experiment," in which we vary the fraction 
of firms utilizing tournaments in our lab economies and the return on the public good is allowed to increase under the conservative assumption that effort levels do not also increase. ${ }^{10}$ Given the original composition of three-person firms was random and the return on the public good was arbitrary, we re-sampled three firms at a time randomly (with replacement) from the population to form new nine-person lab economies and asked what would happen to mean welfare in these lab economies as the fraction of tournament firms increased along with the productivity of the public good. We then calculated "prediction intervals" that contained $95 \%$ of the means for each mixture of firms and return on the public good.
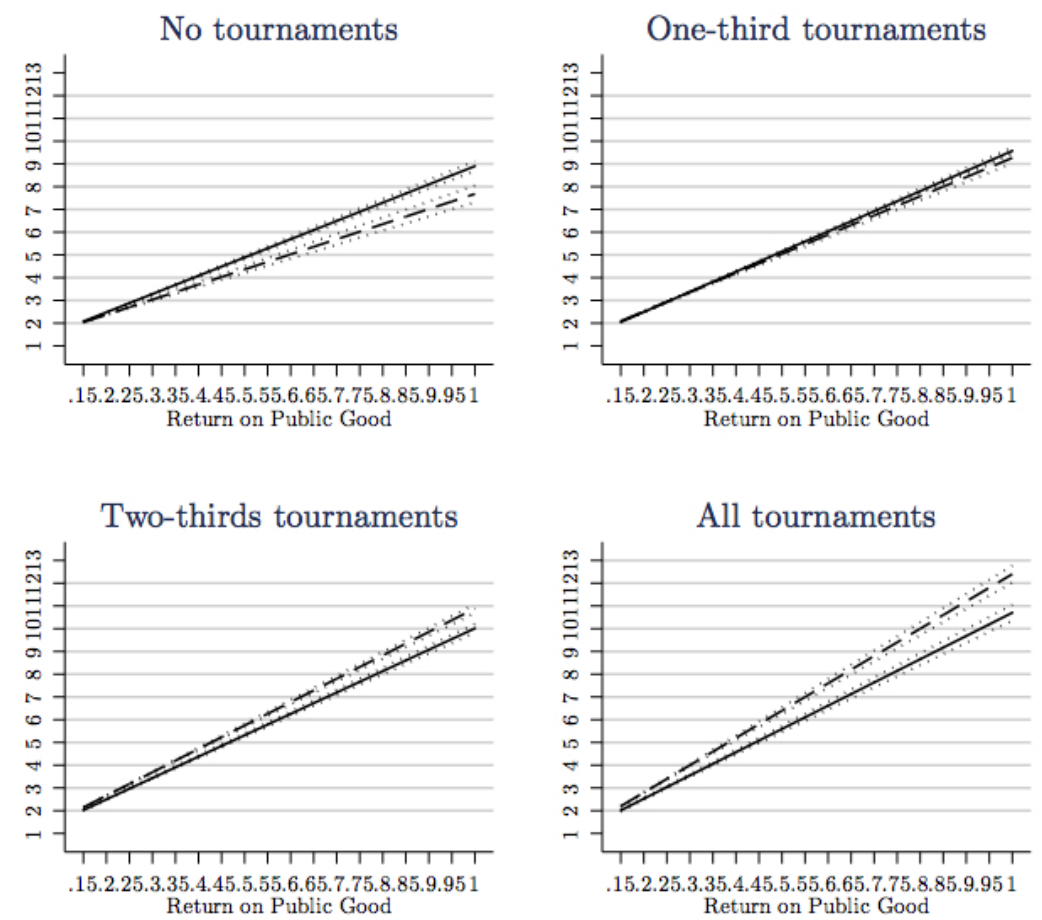

Flat ----- Progressive

$95 \%$ C.I.

Figure 7: Mean Re-sampled Economy-Level Welfare (by tax code and tournament frequency)

\footnotetext{
${ }^{10}$ Recall that the return on the public good, $\alpha$, is in the numerator of optimal effort under both incentive structures. Further, given the linear nature of the public good provided, effort levels are dominant and invariant to the expected effort levels of other workers.
} 
The four possible realizations of this re-sampling exercise are summarized in Figure 7, which plots both estimated mean welfares and the prediction intervals around these. Beginning in the upper left panel, the case where all the firms use piece rate incentives, it comes as no surprise, given the distortions observed in the effort data, that average lab economy welfare is lower under progressive taxation, or that the difference between the tax code increases as the return on the public good improves. While our results replicate those in Figure 6 when the return on the public good is low (i.e., $\alpha=0.15$ ), because both effort and taxes were higher under the flatish tax code, as the return on the public good increases, the difference in the benefits of taxation expand, providing another rationale for the standard result.

The situation changes, however, as more firms adopt tournament incentives. In economies in which just one-third of the firms adopt tournaments (top right panel of Figure 7), the welfare gap disappears and the progressive code provides welfare equivalent to that under the flatter code, regardless of the return on the public good. Further, past the 1/3 tournaments "tipping point," a new welfare gap emerges, one in which workers are better off, on average, under the progressive code. When two-thirds of the firms use tournaments a small gap opens and for intermediate returns on the public good becomes significant. When all firms use tournaments to incentivize their workers, progressive taxation clearly increases welfare (bottom right panel). Competitors largely ignore increases in the progressivity of the tax code when choosing how hard to work, considerably more tax revenue is collected and for even modest returns on the public good, workers are significantly better off, on average. Contrary to the standard, textbook, treatment of a backward bending labour supply curve often based on workers incentivized by piece rates, in an economy where tournament-based incentives or other competitions are the norm, progressive taxation may simultaneously expand the public goods provided and enhance welfare.

\section{References}

Abeler, Johannes and Simon Jaeger. 2013. "Complex Tax Incentives: An Experimental Investigation," IZA Discussion Paper 7373.

Altmann, Steffen; Falk, Armin; and Matthias Wibral. 2012. "Promotions and Incentives: The Case of Multi-Stage Elimination Tournaments," Journal of Labor Economics, 30(1), 149-174. 
Amaldoss, W. and Amnon Rapoport. 2009. "Excessive Expenditure in Two-Stage Contests: Theory and Experimental Evidence," F. Columbus, Game Theory: Strategies, Equilibria, and Theorems. Hauppauge, NY: Nova Science Publishers.

Astor, Philipp; Adam, Marc; Jaehnig, Caroline and Stefan Seifert. 2013. "The Joy of Winning and the Frustration of Losing: A Psychophysiological Analysis of Emotions in First-Price Sealed-Bid Auctions," Journal of Neuroscience, Psychology, and Economics, 6(1), 14-30.

Charness, Gary and Peter Kuhn. 2011. "Chapter 3 - Lab Labor: What Can Labor Economists Learn from the Lab?," A. Orley and C. David, Handbook of Labor Economics. Elsevier, 229-330.

Chen, Hue; Ham, Sung and Noah Lim. 2011. "Designing Multiperson Tournaments with Asymmetric Contestants: An Experimental Study," 57(5), 864-883.

Cooper, David and Hanming Fang. 2008. "Understanding Overbidding in Second Price Auctions: An Experimental Study," Economic Journal, 118(532), 1572-1595.

Dechenaux, Emmanuel; Dan Kovenock and Roman Sheremeta. 2012. "A Survey of Experimental Research on Contests, All-Pay Auctions and Tournaments," Chapman University Working Paper.

Delgado, Mauricio; Schotter, Andrew; Ozbay, Erkut and Elizabeth Phelps. 2008. "Understanding Overbidding: Using the Neural Circuitry of Reward to Design Economic Auctions," Science, 321(26 September), 1849-1852,

Diamond, Peter and Emmanuel Saez. 2011. "The Case for a Progressive Tax: From Basic Research to Policy Recommendations," Journal of Economic Perspectives, 25(4), 165-190.

Dohmen, Thomas; Falk, Armin; Fliessbach, Klaus; Sunde, Uwe and Bernd Weber. 2011. Relative versus Absolute Income, Joy of Winning, and Gender: Brain Image Evidence," Journal of Public Economics, 95(3-4), 279-285

Dworkin, Ronald. 2000. Sovereign Virtue: The Theory and Practice of Equality. Cambridge, Harvard University Press.

Fischbacher, Urs. 2007. "Z-Tree: Zurich Toolbox for Ready-Made Economic Experiments." Experimental Economics, 10(2), 171-78.

Gneezy, Uri; Muriel Niederle and Aldo Rustichini. 2003. "Performance in Competitive Environments: Gender Differences." Quarterly Journal of Economics, 118(3), 1049-74.

Goolsbee, Austan. 2000. "What Happens When You Tax the Rich? Evidence from 
Executive Compensation." Journal of Political Economy, 108(2), 352-378,

Keane, Michael. 2011. "Labor Supply and Taxes: A Survey." Journal of Economic Literature, 49(4), 961-1075.

Kraekel, Matthias. 2008. "Emotions in Tournaments," Journal of Economic Behavior and Organization, 67(1), 204-214.

Lazear, Edward P. and Sherwin Rosen. 1981. "Rank-Order Tournaments As Optimum Labor Contracts." Journal of Political Economy, 89(5), 841-864.

Lazear, Edward P. and Paul Oyer. 2004. "Internal and External Labor Markets: A Personnel Economics Approach." Labour Economics, 11(5), 527-554.

Lemieux, Thomas, W. Bentley MacLeod and Daniel Parent. 2009. "Performance Pay and Wage Inequality." Quarterly Journal of Economics, 124(1), 1-49.

Levy-Garboua, Louis; David Macsclet and Claude Montmarquette. 2009. "A Behavioral Laffer Curve: Emergence of a Social Norm of Fairness in a Real Effort Experiment." Journal of Economic Psychology, 30(2), 147-61.

Mirrlees, James A. 1971. An Exploration in the Theory of Optimal Income Taxation," Review of Economic Studies, 38(2), 175-208.

Okun, Arthur. 1975. Equality and Efficiency: The Big Trade-off. Washington DC: Brookings Institution.

Osterman, Paul and M. Diane Burton. 2009. "Ports and Ladders: The Nature and Relevance of Internal Labor Markets in a Changing World." The Oxford Handbook of Work and Organization (online). DOI 10.1093/oxfordhb/9780199299249.003.0022.

Ottone, Stefania and Ferruccio Ponzano. 2007. "Laffer Curve in a Non-Leviathan Scenario: A Real Effort Experiment." Economics Bulletin, 3(47), 1-7.

Parco, J.; Amnon Rapoport and W. Amaldoss. 2005. "Two-Stage Contests with Budget Constraints: An Experimental Study." Journal of Mathematical Psychology, 49(4), 320-38.

Persson, Mats and Agnar Sandmo. 2005. "Taxation and Tournaments." Journal of Public Economic Theory, 7(4), 543-59.

Piketty, Thomas; Emmanuel Saez and Stefanie Stantcheva. 2014. "Optimal Taxation of Top Labor Incomes: A Tale of Three Elasticities." American Economic Journal: Economic Policy, 6(1). 230-271.

Saez, Emmanuel. 2001. "Using Elasticites to Derive Optimal Tax Rates, Review." Review of Economic Studies, 68(x), 205-229.

Sheremeta, Roman. 2010. "Experimental Comparison of Multi-Stage and One- 
Stage Contests." Games and Economic Behavior, 68(2), 731-47.

Sillamaa, Mary-Anne. 1999a. "How Work Effort Responds to Wage Taxation: A Non-Linear Versus a Linear Experiment." Journal of Economic Behavior \& Organization, 39(2), 219-33.

. 1999b. "How Work Effort Responds to Wage Taxation: An Experimental Test of a Zero Top Marginal Tax Rate." Journal of Public Economics, 73(1), 125-34. . 1999c. "Taxpayer Behavior in Response to Taxation: Comment and New Experimental Evidence." Journal of Accounting and Public Policy, 18(2), 165-77.

Sutter, Matthias and Hannelore Weck-Hannemann. 2003. "Taxation and the Veil of Ignorance - a Real Effort Experiment on the Laffer Curve." Public Choice, 115(1/2), 217-40.

Swenson, Charles. 1988. "Taxpayer Behavior in Response to Taxation." Journal of Accounting and Public Policy, 7(1), 1-28.

van Dijk, Frans; Joep Sonnemans and Frans van Winden. 2001. "Incentive Systems in a Real Effort Experiment." European Economic Review, 45, 187-214.

Waldman, Michael. forthcoming. "Classic Promotion Tournaments Versus MarketBased Tournaments." Industrial and Labor Relations Review.

\section{Appendix}

\subsection{Experiment Instructions (for progressive piece rate then tournament)}

Introduction

Thank you for participating in our study today. In addition to the $\$ 5$ that we will pay you just for showing up, you now have the opportunity to earn an additional sum that will depend on your actions, as well as the actions of others in this experiment session. Your total earnings will be paid, in cash, at the end of the session.

Please note that any and all actions and decisions that you make in the exercises or responses you provide are strictly confidential and anonymous. We intend to use the data collected from our study for academic work as it relates to economic decision making. To assure your performances are confidential, we ask you to not speak to each other until the entire study is completed.

A lab assistant will read all subsequent instructions aloud to you. Please read along 
with the lab assistant as he reads them to you. If you have any questions while these instructions are being read, please raise your hand and we will attempt to answer them.

This experiment will have three parts, the first of which will last 3 minutes; the final two will each last 12 minutes. At the beginning of each part of the experiment, please enter your Middlebury College Mailbox number when prompted, in order to ensure payment. At the end of the session, we will call you individually by number for payment.

\section{Motivation and Background}

In this experiment, the 9 participants are organized into 3 "firms" that form a small scale economy in which people work in their firms, pay taxes, and the taxes are used to provide benefits for the citizens. After an unpaid practice period (lasting 3 minutes), there will be two 12 minute work periods in which each of you will work on a task in your firm with two other randomly assigned employees for money. After each of the periods, your total earnings which will depend on how hard you work, will be calculated and taxed. The total tax revenue collected in the economy (i.e., from all 9 of you) will then generate monetary benefits for all citizens.

Specifically, The work that you will be doing is to decode numbers into letters. For each set of numbers that you decode correctly, 10 cents of earnings are created. Once your total earnings for the period are settled they will be taxed using the following tax code:

o Any earnings up to $\$ 2.00$ will be taxed at $5 \%$.

o Additional earnings between $\$ 2.01$ and $\$ 3.00$ will be taxed at $17 \%$.

o Additional earnings between $\$ 3.01$ and $\$ 4.00$ will be taxed at $32 \%$.

o Additional earnings between $\$ 4.01$ and $\$ 5.00$ will be taxed at $47 \%$.

o Additional earnings over $\$ 5.01$ will be taxed at $64 \%$.

The total tax revenue for the period will be the sum of all the taxes collected from the 9 citizens. The total tax revenue generates a benefit for each of the citizens. For every dollar collected in tax revenue, each and every participant earns a benefit of 15 cents. At the end of the experiment your total earnings will be your $\$ 5$ show up fee plus your after tax (and after benefit) earnings from the two periods. When decoding, please make all entries as lower-case letters. If your entry is incorrect, you will get an error message and will have to retry.

Specific Instructions for Period 1 
In this experiment you will be completing a production task that consists of decoding numbers into letters. The numbers that you will be decoding are randomly drawn. After you submit an answer on the computer, you will be given a new set to decode. The production task of decoding numbers in Period 1 will last for 3 minutes. At the end of 3 minutes you will be presented with a summary of how many problems you answered correctly. There will be no payments for the first round, as it is designed to familiarize you with the task before the longer second round and third rounds.

Specific Instructions for Period 2

In Period 2 of the experiment, you will have 12 minutes to decode as many sets of numbers as you like. Your before tax earnings will be calculated by paying you 10 cents for each of the number sets that you successfully decode. Your after tax earnings will be calculated in two parts: First, you will be taxed according to the code described above. Second, after the total tax revenue for the economy is summed each person will receive a benefit of 15 cents for each dollar of tax revenue collected.

Here is an example: for simplicity, suppose that all nine of you decode 40 sets correctly, you will each earn $\$ 4.00(40 \times \$ 0.10)$ before taxes and you will each pay 59 cents in taxes calculated as follows: Tax $=\{(\$ 2 \times 0.05)+(\$ 1 \times 0.17)+(\$ 1 \times 0.32)\}=$ $\$ 0.59$. The total tax revenue will be the sum of the taxes collected from all 9 of you or, in this case, $\$ 5.31(\$ 0.59 \times 9)$. The benefit that you each receive from the taxes collected is, therefore, $\$ 0.80(\$ 5.31 \times 0.15)$. Hence, your final, after tax, earnings for the period would be $\$ 4.21(\$ 4-\$ 0.59+\$ 0.80)$.

Are there any questions?

Specific Instructions for Period 3

In Period 3 of the experiment, you will have 12 minutes to decode as many sets of numbers as you like. For each number set that is correctly decoded by a member of your firm (recall that you have been randomly assigned to a group with two other citizens), 10 cents of before tax earnings are generated for the firm. Your after tax earnings will be calculated in three parts. First, total firm earnings will be distributed according to the following tournament pay structure: $60 \%$ of the total firm earnings will go to the group member who decoded the most sets, $30 \%$ will go to the group member who decoded the second most sets and $10 \%$ will go to the group member who decoded the third most sets. Second, you will be taxed according to the code described above. Third, after the total tax revenue for the economy is summed each person will receive a benefit of 15 cents for each dollar of tax revenue collected. 
Here is an example: suppose that you solve 35 sets correctly, and the other two members of your firm solve 30 and 40 problems correctly. In total, the firm solved 105 sets correctly and this translates into $\$ 10.50$ of earnings. The person who solved the most gets $\$ 6.30(\$ 10.50 \times 0.6)$, you get $\$ 3.15(\$ 10.50 \times 0.3)$ and the person who solved the fewest receives $\$ 1.05(\$ 10.50 \times 0.1)$.

You would pay $\$ 0.32$ in taxes $\{(\$ 2 \times 0.05)+(\$ 1 \times 0.17)+(\$ 0.15 \times 0.32)\}$ and further suppose that the other two firms generated the same outcome as yours did. In that case, the total tax revenue for the economy would be $\$ 7.35$. The benefit that you each receive from the taxes collected is, therefore, $\$ 1.10(\$ 7.35 \times 0.15)$. Hence, your final, after tax, earnings for the period would be $\$ 3.93(\$ 3.15-\$ 0.32+\$ 1.10)$.

Are there any questions?

\subsection{Auxiliary Empirics}

\begin{tabular}{cccc}
\hline & Flat(ish) & Progressive & p-value \\
\hline Female (I) & $0.42(0.50)$ & $0.43(0.50)$ & 0.93 \\
Competitive (I) & $0.72(0.45)$ & $0.81(0.39)$ & 0.28 \\
Government Wasteful (I) & $0.15(0.36)$ & $0.38(0.49)$ & 0.01 \\
Conservative (I) & $0.19(0.39)$ & $0.15(0.36)$ & 0.64 \\
\hline
\end{tabular}

Note: means and (standard deviations); p-values from mean comparisons.

Table 3: Treatment Balance. 


\begin{tabular}{|c|c|c|c|c|c|c|}
\hline \multirow[b]{3}{*}{ Progressive Tax Code (I) } & \multicolumn{2}{|c|}{$(1)$} & \multicolumn{2}{|c|}{$(2)$} & \multicolumn{2}{|l|}{$(3)$} \\
\hline & \multicolumn{2}{|c|}{ No Controls } & \multicolumn{2}{|c|}{ Controls } & \multicolumn{2}{|c|}{$\mathrm{Ctl}+$ Inter } \\
\hline & $-2.87^{*}$ & $(1.71)$ & $-3.66^{* *}$ & $(1.78)$ & $-10.69^{* * *}$ & $(2.44)$ \\
\hline Tournament (I) & $2.96^{*}$ & $(1.66)$ & 2.80 & $(1.70)$ & -0.05 & $(2.36)$ \\
\hline Progressive $\times$ Tournament $(\mathrm{I})$ & 1.95 & $(2.57)$ & 2.32 & $(2.57)$ & 2.28 & $(2.46)$ \\
\hline Second Work Period (I) & 0.08 & $(1.32)$ & 0.23 & $(1.32)$ & 0.49 & $(1.29)$ \\
\hline Female (I) & & & 0.53 & $(1.12)$ & -2.95 & $(1.89)$ \\
\hline Competitive (I) & & & $2.68^{* *}$ & $(1.34)$ & -0.44 & $(1.99)$ \\
\hline Government Wasteful (I) & & & 1.49 & $(1.09)$ & 2.02 & $(1.85)$ \\
\hline Conservative (I) & & & $-2.45^{*}$ & $(1.32)$ & $-6.45^{* * *}$ & $(2.10)$ \\
\hline Progressive $\times$ Female $(\mathrm{I})$ & & & & & $7.16^{* * *}$ & $(2.16)$ \\
\hline Tournament $\times$ Female $(\mathrm{I})$ & & & & & 0.14 & $(2.24)$ \\
\hline Progressive $\times$ Competitive $(\mathrm{I})$ & & & & & $4.22^{*}$ & $(2.45)$ \\
\hline Tournament $\times$ Competitive $(\mathrm{I})$ & & & & & 3.00 & $(2.56)$ \\
\hline Progressive $\times$ Gov't Wasteful $(\mathrm{I})$ & & & & & -1.53 & $(2.18)$ \\
\hline Tournament $\times$ Gov't Wasteful $(\mathrm{I})$ & & & & & 0.33 & $(2.09)$ \\
\hline Progressive $\times$ Conservative $(\mathrm{I})$ & & & & & $6.88^{* * *}$ & $(2.60)$ \\
\hline Tournament $\times$ Conservative $(\mathrm{I})$ & & & & & 2.63 & $(2.62)$ \\
\hline Constant & $45.18^{* * *}$ & $(1.14)$ & $43.29^{* * *}$ & $(1.50)$ & $47.56^{* * *}$ & $(1.68)$ \\
\hline Observations & 21 & & 21 & & 210 & \\
\hline Adjusted $R^{2}$ & 0.0 & & 0.0 & & 0.12 & \\
\hline
\end{tabular}

Note: Dependent variable is output; OLS with robust (standard errors); ${ }^{*} \mathrm{p}<0.10,{ }^{* *} \mathrm{p}<0.05,{ }^{* * *} \mathrm{p}<0.01$.

Table 4: A Full Set of Output Determinants. 